\section{0-INCH CASSEGRAIN/COUDE}

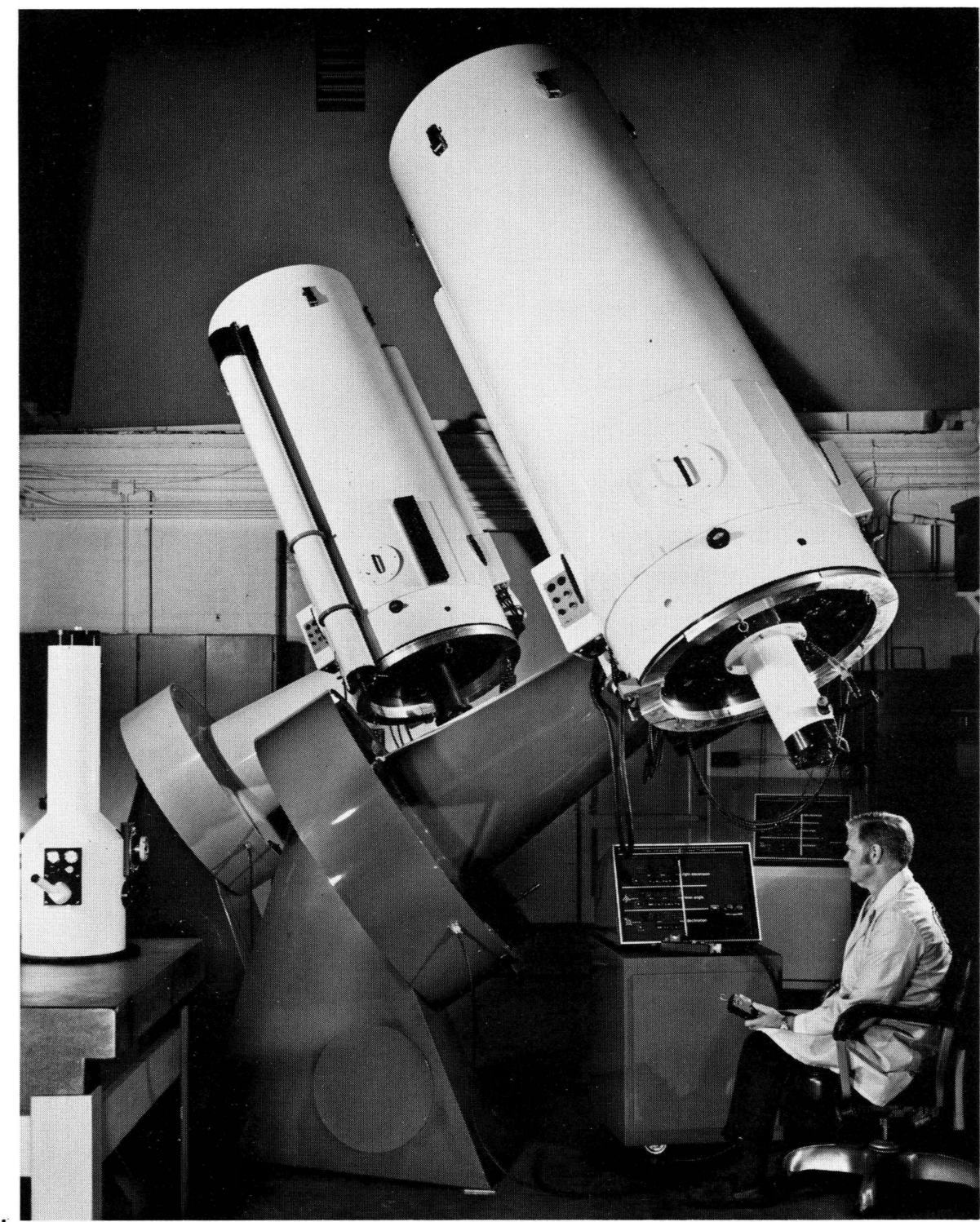

These Boller \& Chivens instruments are based on our standard 24-inch telescope, and use many of the same features. The declination drive is enlarged to handle the increased capacity. The primary mirror is supported by a sixpoint whiffletree back system and a mercury-belt edge system. The 30-inch design offers a 50 percent increase in light-gathering capacity over our 24-inch reflector, at modest cost. Pictured above are the University of Nebraska (foreground) and University of Washington (background) Cassegrain/coude versions of this popular instrument.

LED large-character displays of right ascension, hour angle, and declination, with readily available BCD outputs, in a compact control console, are now standard equipment.

The Model 26767 Spectrograph, pictured at left, offers a proven economical and professional approach to Cassegrain spectroscopy. For prime astronomical instruments and accessories, you can turn with confidence to Boller \& Chivens.

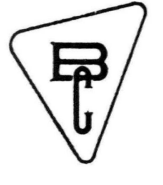

Boller \& Chivens Division-where precision is a way of life.

\section{PERKIN-ELMER}

916 MERIDIAN AVENUE • SOUTH PASADENA, CALIFORNIA

Member American Astronomical Society

\section{Book Reviews}

ATLAS OF OPTICAL PHENOMENA, SUPPLEMENT. by M. Cagnet, M. Francon and S. Mallick. Springer-Verlag, New York, Heidelberg, Berlin 1971. 15 plates with text, $\$ 25.50$

The new supplement to the Atlas of Optical Phenomena is a luxury that most of us in optics will want to indulge in. It contains 15 beautifully reproduced plates (most of which are in color) of the same high quality as those found in the original atlas. Each plate is accompanied by a clearly written text (German, French and English) and explanatory diagrams showing the set-ups used in obtaining the photographs.

The first two color plates show a variety of different types of white light fringes, including patterns with both white and black central fringes obtained with Michelson and Fizeau type interferometers. These are followed by another color plate showing typical white light fringe patterns obtained with a scatterplate interferometer. In a black and white plate I believe a new record may have been set in showing 40 rings of an Airy disc diffraction pattern! The next color plate shows some lovely photographs of crystals between crossed polarizers illuminated by white light. The interference patterns obtained with a convergent beam of polarized white light passing through birefringent crystals and viewed through an analyzer are shown in two more color plates. Following this is an interesting comparison of the white light interference patterns produced by placing a candle flame in both Michelson and polarization interferometers. Two further color plates illustrate the dramatic interferograms which can be obtained with the technique of polarization interference contrast. A further color plate shows a very effective use of polarization interferometry in wind tunnel experiments, and illustrates the advantages of this technique over the more conventional Schlieren photography. Plate number 12 shows some examples of photography through a polarization interference microscope. The final three plates are in black and white and are concerned with holography. The first of these plates is a fairly standard pair of photographs showing reconstructions of a hologram where the camera is focused on different planes in the three dimensional reconstruction. The final two plates show a variety of examples of the use of holographic interferometry in which two exposures are made: small perturbations to the object, occurring between the two exposures, are manifest in the form of an interference pattern between the pair of reconstructed wavefronts. 

I find very little to criticize in this rather opulent volume: I can think of a variety of optical phenomena which might have been included (such as color holography and a variety of optical moiré techniques), but that only suggests that we can look forward to another supplement sometime in the future.

M. Hercher Institute of Optics University of Rochester Rochester, New York 14627

OPTICAL FUNDAMENTALS OF UNDERWATER PHOTOGRAPHY by Gomer T. McNeil, Mitchell Camera Corporation Photogrammetry Division, Rockville, Maryland 1972, 119 pages, $\$ 7.50$

The second edition of Optical Fundamentals of Underwater Photography provides a slightly revised and expanded hard-cover version of the original spiralbound edition. It will be found informative and useful to serious underwater photographers and system designers interested in the performance of lenses and ports.

Optical problems in underwater photography are more complex than for normal photography, since the object space has a substantially different (higher and somewhat variable) index of refraction compared to that in the camera or image space. Ambiguous terminology has also tended to further confuse the issues. Mr. McNeil has done an outstanding job of clearly defining his terms and of relating optical performance to basic principles. His logical presentations, numerous simple numerical examples and excellent diagrams and graphs will appeal to the nonspecialist. The book covers such important topics as: object and image distance relations for thin and thick lenses, flat and dome ports, distortion, depth of field, lens speed, and camera calibration. Analysis of the optical system of an underwater panoramic camera serves as a practical review of the basic optical fundamentals presented in the earlier chapters.

One chapter serves to introduce the reader to the attenuation and scattering of light in water. However, the theory and data are not sufficiently developed to allow prediction of image contrast or resolution.

Larry E. Mertens RCA Deep Look Project RCA/DL, Hgr. B Patrick Air Force Base Florida 32925

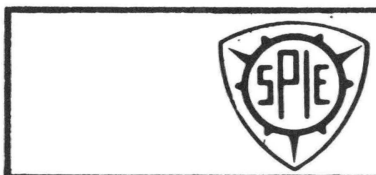

CAMERA AND LENS, by Ansel Adams. Morgan and Morgan, New York. 304 pages 1971. $\$ 12.00$

This enlarged second edition of Ansel Adams' well-known "Camera and Lens" is a real bargain at $\$ 12.00$. In it, Adams shares with the reader many of the secrets that have made him one of the world's greatest photographers. The excellent reproductions of 80 of his photographs are well worth the cost of the book, quite apart from 300 pages of fine print packed with valuable information. Indeed, it is hard to think of any item of photographic equipment that is not thoroughly discussed here.

The book is directed mainly towards the professional or advanced amateur photographer who desires to make the best possible use of larger-format cameras from $2 \frac{1}{4} \times 2 \frac{1}{4}$ inches up. The correct use of a view camera with its swings and rising front is discussed in detail, as also is the difficult problem of correct exposure determination. Establishing the scale and perspective in a picture is an important topic that receives full attention. The intelligent application of these matters is the mark of the expert photographer, and

WE CAN DO MORE TOGETHER

JOIN S.P.I.E.

\section{Compact - Light Weight - Reliable - Simple Operation \\ THE ORIGINAL DEARING ON-CAMERA NUMERIC TIMING SYSTEM}

\section{Numeric Digits Recorded from a Two Wire IRIG Signal Input}

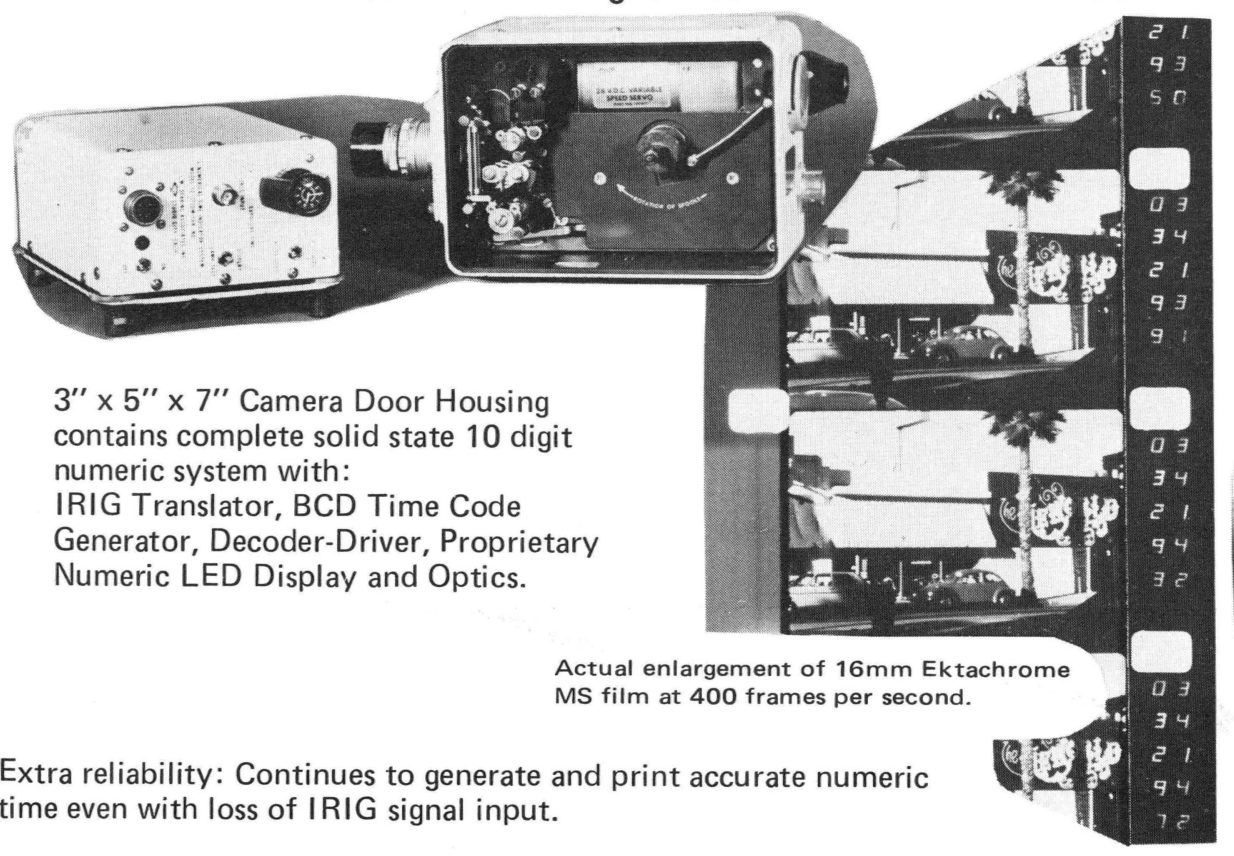

Standard model records to $23 \mathrm{hrs}$. 59 min. $59.9999 \mathrm{sec}$. of numeric real time on each frame "synced" with picture exposure.

Imaged between $16 \mathrm{~mm}$ perforations. Adaptable to $16,35,70 \mathrm{~mm}$ framing cameras to $500 \mathrm{fr} . / \mathrm{sec}$.

Other numeric and serial time code options available.
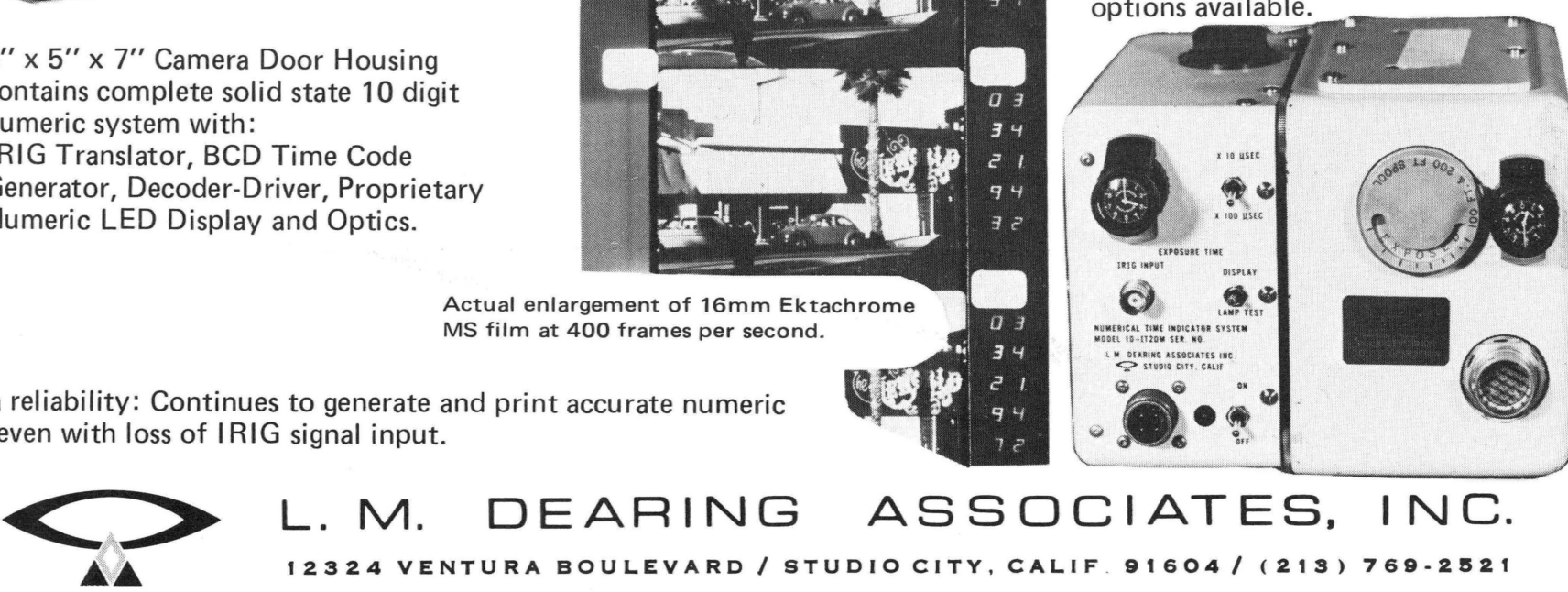
Adams stresses that the photographer must always dominate his equipment and not vice versa.

The selection and use of apparatus is really the meat of this valuable book. Larger cameras of all types, including Polaroid, are described, as are light sources and light meters, flash units, lenses, shutters, filters, and the available negative materials for black-and-white and color photography. Each topic is well illustrated, often with Adams' own photographs. The problems of correctly exposing scenes containing both very bright and dark areas are considered in explanation of the author's 'zone' system. Numerous cameras and lenses are listed, with many explanatory comments; the Calumet and Hasselblad appear to be the author's favorites. There is a penetrating discussion of lenses and photographic optics, while such matters as camera movements and tripods receive full attention. Typical of the whole book is the picture on page 63 of the author standing on the roof of a station wagon aligning an $8 \times 10$ tripod camera!

The long chapter on darkroom manipulations is unusual but most valuable to the practical photographer. Even little matters like counting the ticks of a clock to judge short time intervals, and how best to wash film-pack negatives, are given their due attention. Darkroom layout, water supply and sinks, enlargers, safelights, printing frames, and the mixing of chemicals, are treated as if they were as important as the camera itself.
Every working photographer should be required to possess and read this remarkable book.

R. Kingslake Institute of Optics University of Rochester Rochester, New York 14627

\section{IMAGING TECHNIQUES FOR TESTING AND INSPECTION SEMINAR PROCEEDINGS VOLUME 29 \\ MEETING HELD}

FEBRUARY 14, 15, 1972

\section{LOS ANGELES, CALIFORNIA}

Many important techniques for non-destructive testing and inspection rely upon the formation and analysis of images. The purpose of this meeting was to review the basic principles and describe the current state of the art in these uses of imaging. Nineteen papers were presented on such techniques as $x$-ray and neutron imaging, pulse-echo, holographic and acoustical imaging on a variety of conventional as well as unconventional optical methods. Emphasis was on the application of these techniques to the problems of non-destructive testing.

Copies of the proceedings are available from SPIE National Office, P.O. Box 288, Redondo Beach, Calif. 90277.

SPIE MEMBERS - \$15.00 NON-MEMBERS - $\$ 24.00$

\section{MEETING REPORTS}

\section{SECURITY, SURVEILLANCE AND} LAW ENFORCEMENT, SPIE Seminar held, September 20 \& 21, 1972 at New York City

On the twentieth and twenty-first of September ' 72 the SPIE held a seminar in depth for a group of attendees that were not and probably never would be members. The meeting started with a packed house and, surprisingly, remained that way until almost the end of the second day. There was an associated instrument exhibit that drew good crowds especially during the breaks. It was a seminar for users.

The meeting was designed to inform the nation's law enforcement agencies and officers concerning the sensors and technologies available to them that might find hand guns, explosives, drugs and related material, and those that could extend a man's capabilities when his own normally adequate sensory devices such as normal vision became ineffective because of darkness.

The meeting was designed to be tutorial, and to start from the beginning and carry the non-technical audience well into a qualitative appreciation of what they might be able to do now and within a few years. Further it was hoped that they would get to know the names and addresses of the speakers and know where to turn for objective advice from a group of men who could be approached without fear of conflicting interests getting in their way. It almost came out that way.

Because of our tutorial bent, it became obvious that most of the key papers would probably have to be invited, and the contributed papers screened with strict rules in favor of the audience. As a result relatively few contributed papers were accepted. . and we know now there should have been fewer. For in spite of much correspondence with the authors about our ground rules and objectives, and the actual reading of just about every final paper BEFORE presentation, there were a series of jolting surprises as some of the more hardware-oriented speakers took off on presentations that addressed the non-existent engineers and physicists in the audience and completely lost and

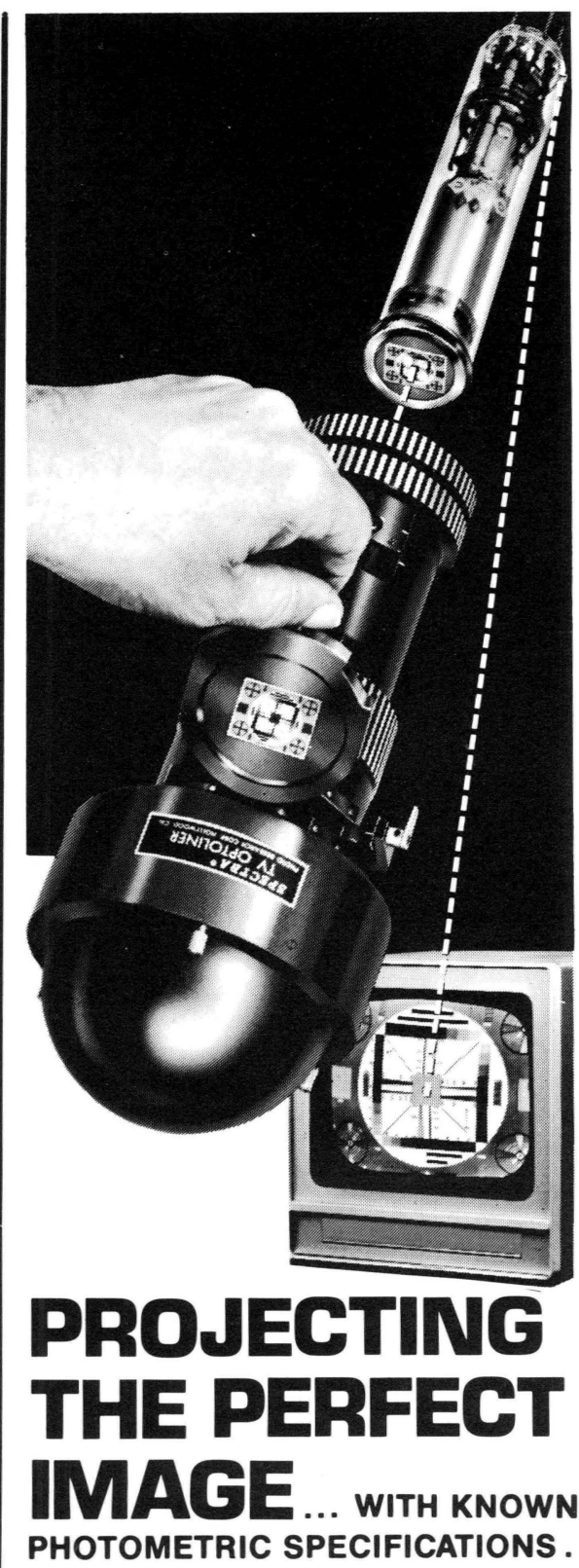

CONCERNED WITH LINEARITY • GEOMETRIC DISTORTION • RESOLUTION - LUMINOUS SENSITIVITY • REGISTRATION - TRANSFER FUNCTION • OR CONTRAST?

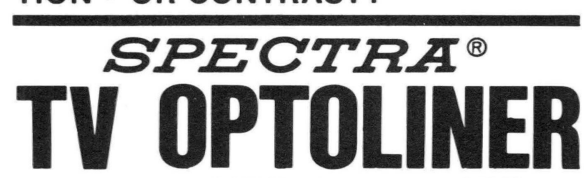

INPUT SCENE GENERATOR

PROJECTS UNIFORM, HIGH RESOLUTION, ILLUMINATED, TEST PATTERNS DIRECTLY ON CAMERA TUBE FACEPLATE OR SENSOR FOR APPLICATIONS SUCH AS: CCTV PRODUCTION \& ENG. - SENSOR EVALUATION - QUALITY CONTROL • SURVEILLANCE CAMERA TESTING

DESIGN, TEST, EVALUATE WITH THE SPECTRA TV OPTOLINER....CALL COLLECT! (213) 849-6017

\section{PHOTO}

A Division of KOLLMORGEN Corporation 3000 N. Hollywood Wy., Burbank, CA 91505 